\title{
Problemática de las Lenguas Nacionales
}

Por ALBERTO ESCOBAR

Un rótulo como el de la "Problemática de las lenguas nacionales" invita a imaginar un crucero de alternativas y, llevados un tanto o un mucho por el clima de nuestros tiempos, a la toma de conciencia de nuestra responsabilidad mancomunada e individual respecto de las lenguas nacicnales y las disciplinas e institucjones que se ócupan de su estudio y enseñanza. Quisiera subrayar aue no propondré una reflexión acerca del "Problema "del español ol del Dortugués", si por problema se entiende, repito, una coyuntura rastreable en el mecanismo lingüístico de su sistema o el conflicto que pudiera derivar de su situación de contacto con otra lengua, frente a la cual se hallan en competencia en tanto vehículos de comunicación; más bien examinaré el conjunto de factores extralingüísticos; de factores o situaciones que en esta segunda mitad del siglo veinte afectan a los países latinoamericanos hasta un grado tal que, a tenor de lo establecido por las otras ciencias sociales, definen el carácter de nuestras sociedades y, en consecuencia, tipifican el ambiente natural en el que las llamadas lenguas nacionales sirven de medios de comunicación y de expresiones de la respectiva cultura. Ello equivale a proyectar una imagen de las lenguas nacionales y de los presupuestos con que podemos interpretar su función, describir su estado, emprender su istudio, practicar su enseñanza, pre..

Letras, Lima 40 (80-81): 1-11, 1968 
sagiar su porvenir, etc., pero en estrictos términos de cuestión social, esto es, como una problemática de las sociedades latinoamericanas antes que como un problema de análisis histórico o sincrónico de la lengua, o de sus rasgos actuales o de las tendencias que anticipan su desarrollo ulterior. En síntesis, pensar cuál es el papel de las lenguas nacionales en las sociedades latinoamericanas de hoy, qué alternativas podemos avizorar como urgentes, y en qué medida hay una tarea lingüística y pedagógica que dependen de la opción que ejecute. mos, de acuerdo con el grado de la conciencia que sobre esta problemática nos parezca pertinente.

2. Hasta qué punto las consideraciones que hemos tenido en cuenta, así como las conclusiones a las que lleguemos merecen entenderse como válidas en el marco general de Hispanoamérica, es un riesgo que debe inducirnos a obrar con cautela e incluso a auspiciar un explicable recelo. Con seguridad, mi información y los datos y fuentes que manejo no son lo completo ni homogéneo que se requeriría para afirmar con énfasis pleno que el cuadro que contemplo responde con absoluta fidelidad a la situación particular de cada país, a las modalidades que esta problemática asume en cada uno di ellos, o a las respuestas que, de parte de personas e instituciones, ha suscitado en concreto. De otro lado, es posible que la línea de mi reflexión sea más válida para el mundo hispanohablante que para el Brasil y el Caribe no hispánico. Si? embargo, la idea de que por debajo de las lvariantes específicas prevalece una condición común en nuestras sociedades, y que, aunque sea en términos relativos, es factible hablar de una tradición igualmente compartida en lo que toca a las reflexiones sobre la lengua y la lingüística, nos lleva a pensar que las meditaciones aue se desprenderán de este planteo, si bien no desembocarán en un juicio generalmente aceptable, de cualquier modo, suscitarán la necesidad de esclarecer en las regiones singulares el enfoque correspondiente. En postrer término, es el enfoque o perspectiva para contemplar la problemática lo que nos parece válido $y$, por ende, la contribución más segura de nuestro trabajo.

3. ¿Hasta dónde se puede invocar una actitud común o una manera análoga en el encaramiento de las cuestiones relativas a la lengua en la América Latina? ¿Es posible soste. ner la existencia de un criterio difundido y constante sin alterar gravemente la realidad histórica ni llegar a su falseamiento? Entiéndase que no se procura emparejar el avance dé los estudios linguístics, ni se trata de nivelar la capacidad 
de personas e instituciones, ni de sostener la equivalencia es. tricta de los programas, métodos y textos de enseñanza, ni siquiera de cotejar con porcentajes la difusión de la lengua nacional, ni el empeño educativo de los estados, ni la calidad de los escritores o el prestigio de que gozan los gramáticos o los poetas. Se trata de establecer si los usuarios y quienes por razones diversas se ocupan del estudio de la lengua, de su enseñanza o de la creación literaria en nuestros diferentes países, están imbuídos de una semejante actitud respecto d: la función de la lengua nacional, de su peso en el proceso educativo, de los objetivos que incitan a estudiarla, de los paradigmas que se pretenden en las correspondientes instancias, en suma, del trajín a que ella nos convoca. Vistas así las co. sas, parece menos arbitrario postular que la común actitud procede de una suerte de premisa que, a su turno, se inspira en la difusión de la lengua española, propagada a consecuen. cia de la dominación peninsular en el pasado.

Vale esto decir que los antecedentes históricos solventan la convicción de que Hispanoamérica disfruta del privilegio de una lengua común, el español, y que prevalece el criterio de lo unitario sobre el de la diferenciación regional. Este juicio no sólo ha sido utilizado como un elemento justificador de la conquista, por quienes en el debate histórico se creyeron en la necesidad de justificar el periodo del dominio colonial, sino que, también lo hemos suscrito quienes en nuestro continente advertíamos la conveniencia de fomentar los rasgos de aglutinación en contra de los disgregadores, y ya, desde los años de Bello y de Cuervoghasta dos lúltimosensayos acerca de la cuestión del español en América, concebíamos la unidad por la lengua como un presupuesto de una América identificada en el nivel lingüístico, en anticipo del cumplimiento de ideales de la integración continental, renovados periódicamente en una suerte de tropismo hacia la integración económica y política, tal como en la actualidad nuevamente se ensaya. En cierta medida, habría que conceder que esta vocación unitaria ha atravesado por etapas diversas, en las que la motivación no es exactamente la misma, pero sí el resultado; véase, por ejemplo, que ella responde, en primer término a los vínculos con la antigua metrópoli; que más tarde se levanta como un ideal opuesto a la fragmentación, una vez que decrece la fuerza niveladora del modelo peninsular; que en otra coyuntura obedece, precisamente, a un signo opuesto, cuando el sustentar ese ideal equivalía a reconocer un rasgo común en América, para diferenciar el "español americano" del "español de la península"; y presumiblemente también la postulación unita- 
ria expresa un gesto cultural defensivo frente a la expansión hegemónica del inglés y del poderío político-económico de los Estados Unidos de América. Pero, aun cuando las razones profundas sean distintas, las consecuencias hacia las que ellas derivan concluyen en una semejante manera de interpretar la realidad linguística hispanoamericana, a saber, en la consagración del valor cohesivo de la lengua, y coherentemente, en la premisa de la identidad supranacional merced al común patrimonio del instrumento lingüístico, por encima y a pesar de la diversidad regional.

4. Seguiría mal nuestro razonamiento quien infiriera que se ha desconocido la gama de matices y variedades regionales existentes en el español americano. Hay sobre el tema una bibliografía rica, en especial sobre las variedades rurales apartadas, que fácilmente disolvería cualquier duda al respecto. De otro lado, téngase en cuenta que nuestra indagación no se reduce al grupo de personas, siempre limitado, que ha tenido por tarea el estudio de la lengua, puesto que lo incluye dentro del sector más vasto, pero capaz de reflexión individual o de adherir a una verdad colectiva; en efecto, hemos mencionado usuarios, investigadores, profesores, escritores, etc. Pero hecha esta salvedad, tengo por legítimo el juicio de que lo constante y tradicional ha sido concebir el español de América como la lengua común de nuestros países, atendiendo preferentemente a sus rasgos unitarios. Ahora bien, no parece sensato descartar el influio que en la elaboración de esta conciencia han jugado los factores de tipo histórico-cultural y político, pero tampoco sería prudente atribuir a ellos, y más aún habida cuenta de su distinto carácter, según hemos visto, la exclusiva responsabilidad en la formación de ese sentimiento tan difundido, y defendido tan ardorosamente, y más por los iniciados que por los legos. Por ello estimo que debe verse como otra causa decisoria el que se haya escogido como punto de referencia la lengua escrita, y, en particular, la literaria, que han valido no sólo como términos de comparación sino, además, como dominante fuente de estudio y de cotejo. Si se liga lo anterior al hecho de que, salvo en un caso, la llegada del español a América aparejó la llegada de la escritura; si se considera el aún crecido porcentaje de analfabetismo que campea en esta parte del mundo; si se recuerda que una de las pocas vías abiertas para la movilidad social, entre nosotros, es la educación formal, y que ésta supone en lo primario el dominio de la escritura; si se añade el prestigio de la literatura española y la vocación notable que ella suscita en nuestros países, se construye un sistema de factores que, de 
uno u otro modo, han obrado concurrentemente para realzar la escritura y reforzar la interpretación del hecho lingüístico desde la realidad de lo literario $y$, en general, de lo escrito. Pero, además, si concedemos que lo escrito y la literatura no sólo inspiraban la imagen de la unidad lingüística, sino que revelándola a su manera, la reforzaban, ya resulta sencillo entender en qué grado la escritura sustituyó a la lengua y cómo al apelarse a la "lengua" de las personas "de más esmerada educación" se tenía presente más que la variedad de niveles de la lengua oral, incluso en el caso de las personas instruidas, el rasero de un modelo consagrado previamente en las páginas escritas.

5. Quizá sea un tanto exagerado proponer que, si lo dicho hasta aquí es exacto, el llamado español americano, como lengua unitaria, es una suerte de ilusión forjada más en el crisol de los ideales americanistas que en la realidad objetivi y analizable que es materia de los estudios técnicos. Quizá este momento y este acto, en el que yo hablo y ustedes me entienden, en una lengua inexistente, pudiera inspirar la fantasía de un Borges, o estimular la captación de lo real maravilloso de parte de un escritor como García Márquez. ¿Cómo y por qué ocurre, pues, este prodigio? Si la lengua común es la que usan las personas de educación más esmerada en cada uno de nuestros respectivos países, pareciera que ella depende de una serie de actos del habla que corresponden con su realización a lenguas, a sistemas, distintos. Daría la impresión de que carece de ubicación geográfica, de cuerpo social orgánico, y que es unaespecie de denguas artificial, de maravilloso artificio, que por ceñirse voluntariamente a un esquema teórico nos obsequia tornando realidad un viejo sueño.

Pero si en mi lugar apareciera alguno de aquellos personajes de la familia Sánchez que el libro de Oscar Lewis ha hecho famosos en el mundo, ¿se lograría la comunicación? Si se entablara un diálogo entre un campesino venezolano y un trabajador de los muelles de Valparaíso, ¿podrían realmente conversar? Recuerdo haber escuchado varios minutos, lleno de estupor, a un niño pobre de Luquillo, en Puerto Rico, sin haber entendido absolutamente nada. Dificultad análoga padecerían ustedes si escucharan conversar en alguna variedad del español andino. ¿Qué es lo que ocurre entonces? ¿Qué es lo que ocurre para que, después de un tiempo en el que nuestro oído gana en habilidad, podamos ser capaces de cerrar el circuito del diálogo? Tengo la impresión de que, para ello, hace falta que se produzcan una serie de reajustes que equivalen 
a un tipo particular de traducciones que. sucesivamente, nos acercan a la lengua común o general o standard, la que, sirviendo como una lingua franca, que es de todos y de nadie, permite que se establezca la comunicación. Sin embargo, si convirtiéramos lo dicho por cualquiera de los supuestos interlocutores a una versión escrita, el papel nos devolvería irreprochablemente descifrado el mensaje oral. Se habría producido de manera instantánea y misteriosa la traducción lingüística. Más adelante veremos las implicancias sociales de este fenómeno y las consecuencias que de él se desprenden; por $\geq_{1}$ momento, parece fuera de duda: 1) no que carezca de existencia el español que en América nos ofrece el rango más amplio de comunicación; sino nue apenas es un nivel de lengua, una suerte de dialecto difunaido por la gente de "educación esmerada", sobre la base del español escrito; 2) que este nivel de lengua es compartido por una porción significativamente pequeña de la población del continente; y 3) que más allá de este refugio, e incluso sin contar las lenguas de origen no hispánico, se perciben los rumores nerviosos de una babel contemporánea.

6. Pues bien, tal es la situación como yo la contemplo. No creo que merezca ser interpretado en el odioso juego de levantar reproches o regatear méritos si digo que, en virtud de la intensidad con que hemos vivido la ilusión de poseer una América linguiísticamente unitaria, hemos alimentado posiciones que en 1967 demandan ser revisadas en su proyección linguiística, educativa, social y política.

En lo linguístico, porque la consecuencia más visible ha sido la natural reducción del campo de estudio, ya porque lo verbal quedara como subsidiario de lo escrito, ya porque lo rural en tanto obsoleto o aberrante adquiriera una cierta pátina atractiva, ya porque el léxico local sustituyera al reconocimiento de los sub-sistemas regionales, ya porque se pospusiera la investigación linguiística en los estratos sociales.

En lo educativo, porque endeudados con la premisa de la lengua común, se procedió a invertir el natural proceso de trabajo, y los textos de enseñanza y de gramática se propusie.. ron afirmar una lengua que, de facto, no poseía el alumno, y por tanto, se dejó de estudiar las variedades habladas para, sobre la base de ellas, conducir al estudiante hasta el nivel de la llamada lengua general.

En lo social, porque al no haberse fundado una base des- 
criptiva de las variantes reales e ignorarse las variantes ligadas a los niveles sociales, la pedagogía no pudo entregar el instrumento lingüístico a los hablantes de extracción popular que requerían de la escuela para compensar la desventaja que su procedencia social les imponía, y, por tanto, al exaltarse el ideal de la corrección y fracasar en el de la enseñanza, se ha contribuido a una discriminación por el nivel de lengua.

$\mathrm{Y}$, finalmente, en lo político, porque dado todo lo anterior, se desprende la incapacidad de usar la lengua para promover la integración de nuestras sociedades y servir a un espíritu de cambio, deviniendo, por el contrario, hacia una valoración conservadora y elitista que condice con el esquema tradicional de la dependencia y jerarquización en las sociedades latinoamericanas.

A pesar de lo dicho, en nuestro descargo podríamos argüir que quienes adherimos nuestro quehacer a la visión del español americano como unidad viviente, no percibíamos el rápido y complejo proceso social que iba definiendo, sin ambages, a las sociedades de nuestros países; y allegados por formación profesional a las humanidades, desconocíamos con gran frecuencia las realidades que desvelaban las ciencias sociales. Pero además, al haber resąltado e insistido en el privilegio que significa acceder a un instrumento de comunicación general, echábamos las hasta entonces únicas bases logradas para sustentar la integración datinoamericana, en pre$\mathrm{coz}$ anticipo de los postulados económico-políticos. Y este sí es un saldo irreversible y positivo, a pesar de su costo.

7. Si por un momento contemplamos el diseño en el que las ciencias sociales resumen las notas salientes de las socieaades latinoamericanas, divisaremos un haz de características que, vistas en conjunto y referidas a la época actual, nos asombran por su impresionante desbalance y por graficar un orden de cosas que no imaginábamos con rasgos tan dramáticos.

En efecto, cuando se piensa en el ritmo de crecimiento de la población latinoamericana, se advierte que este fenómeno adquiere un significado particular, pues ocurre antes de que se produzca la industrialización, que apenas comienza, y antes de que se haya modernizado el régimen que subsiste en la agricultura. Pero, además, se nos descubre que la explosión demográfica latinoamericana está aparejada con el crecimiento inusitado, en valores absolutos y relativos, del sector urbano. 
En la fase que conocemos como nuestra época, ésta de la que somos contemporáneos, el proceso de urbanización es un fenómeno complejo y por lo mismo revelador, dado que manifiesta la falta de coordinación entre los aspectos sociales y económicos del cambio que se está produciendo en el campo y lia ciudad. Las ciudades crecen por una ola de migraciones que provienen de las zonas rurales, y éstas son abandonadas sin que la tecnología llegue a tiempo para reemplazar la mano del hombre, en tanto las ciudades carecen todavía de las oportunidades de trabajo que la industrialización hubiera podido generar. De esta manera, el flujo campesino ha conseguido alterar radicalmente la composición demográfica de las ciudades, y, en algunos países, ha instituído nuevas formas de interacción en las relaciones entre las diversas estructuras socio-culturales, sobre todo en los medios en que coexisten lo occidental y lo indígena.

$\mathrm{Si}$ el esquema anterior lo superponemos a la tradicional polarización social (de riquezas, niveles de instrucción, niveles de vida, salubridad, justicia) de nuestros países; a la lenti. tud con que evolucionan nuestras estructuras sociales y a la estrechez de las vías existentes para la movilidad vertical, a la pluralidad cultural y falta de integración entre los sistemas socio-culturales que explicitan la concurrencia de distintas culturas, poseeremos el marco de referencias dentro del cual deberá insertarse la problemática de las lenguas nacionales en la actualidad.

De lo así expuesto creo que nos importa fundamentalmente lo que viene ocurriendo con las ciudades, y en especial con las capitales, que han sido siempre los focos de regulación en el uso de la lengua oficial.

Cuando nos preguntamos qué ha pasado en la sociedad latinoamericana desde 1945 a la fecha, la respuesta nos remite a este proceso que moviliza al campesino y lo traslada a las ciudades, y en grado mayor a las capitales, incorporándolo a la vida urbana con el bagaje de sus patrones tradicionales. Pues bien, desde el ángulo lingüístico hay que anotar, como efecto de este fenómeno ya descrito, que la relativa facilidad con que se destacaba la norma "culta" y se imponía por su prestigio en la menos heterogénea "ciudad" de hace treinta años, es hoy menos vigente. Hoy es menos estable y aceptada, no tan sólo porque en proporción decrece el número de quienes la cultivan, sino también porque es mayor y más insistente la violencia que sobre ella ejercen las sub-normas de los grupos sociales que se hallan en proceso de adaptación a los 
patrones urbanos, y que al hacerlo están modificando las relaciones entre los diversos sectores de la sociedad citadina. Paralelamente, no puede ignorarse que la nueva composición demográfica en las ciudades ha traído como corolario una masificación en las formas de la comunicación de masas, y que este hecho, que va invadiendo incluso el lenguaje escrito de los diarios sensacionalistas, ocasiona en este nivel el que la hegemonía de la norma culta sea cada vez más restringida.

De lo expuesto no se sigue que el campo haya permanecido sin otra alteración que no fuera el desplazamiento masivo hacia las urbes. Por el contrario, si bien desde fecha menos lejana, "la progresiva pérdida de poder económico y social de los núcleos provincianos de la clase terrateniente tradicional va dando paso a uná estructura económica nueva en el campo, conducida por la ampliación paulatina de un red de mercados pequeños, y el ascenso de una vasta capa de pequeña burguesía comercial". Esto equivale a decir que aparecen grupos y capas sociales intermedias que, como señala Aníbal Quijano, en los países andinos por ejemplo, "se definen étnica y culturalmente entre las culturas dominantes de cada sociedad y entre sus principales subculturas, trastornando y modificando con celeridad los criterios de relación y evaluación social". Este nuevo estado, si se ensambla con el proceso de urbanización, acarrea la difusión de los elementos de la cultura urbana, filtrados por las rutas de la comunicación y de transportes y las nuevas actividades económicas, y valiéndose así mismo de los lmediosede comunicación de masas como el radio portátil, cảdavez decusolmás extendido. Tales son pues los antecedentes, que unidos a la precariedad de la economía agrícola, explican la agitación producida entre las masas campesinas en los últimos años, pero que además evidencian que esa agitación está conectada con los sectores sociales y culturales intermedios y con los grupos urbanos emergentes, en un nuevo y cada vez más vigoroso circuito.

8. Quisiera apoyarme en este bosquejo de las ciencias so.ciales para precisar que, en las ciudades de Latinoamérica dc hace -digamos- cincuenta años, la rigidez de la estratificación social hacía más definidos los deslindes sociales y la consecuente identificación entre -el nivel social y el lingüístico; que entonces, igualmente, la relación entre la ciudad y el campo en ambos planos se regía por una comunicación menos intensa y estaba canalizada por vías más formales. Dentro de este cuadro, la adhesión a la norma de un "español común" que lo tipificábamos por su endeudamiento con el lell- 
guaje escrito y el literario, aparecía como un desvío menos peligroso, por sus consecuencias sociales, de lo que sería hoy, después de acontecido -y una vez puesto en marcha- el rápido proceso de urbanización y las modificaciones paralelas operadas en el campo. Así llegamos al punto capital de esta ponencia. Nuestra tesis reside en el postulado siguiente: la lingüística como ciencia que estudia el lenguaje e influye en la política educativa de las lenguas nacionales, así como en la idea que de la función soc:ial del lenguaje adoptan los grupos dirigentes de nuestros países, no puede desconocer que los cambios producidos en estos países han modificado sustancialmente la realidad social y su complejo cultural, por lo que este orden distinto de la comunidad que debe interactuar con las lenguas nacionales impone que nuestra disciplina revise sus premisas para el trabajo práctico, sus objetivos respecto de la comunidad hablante y las prioridades que ellas señalan a la investigación futura.

Hasta cierto punto, por ejemplo, la impronta decimonónica de la prevalencia de lo unitario sobre lo regional, como base de estudio o política educativa merece revisarse. No porque reneguemos de la utilidad de preservar el nivel de la lerıgua supranacional, sino purque, para afirmarlo, es imprescindible y es urgente seguir - en la realidad de los hechos lin.. guiísticos- las vías que iraducen ese acomodamiento que trastorna los patrones culturales y linguísticos en la urbe. Debemos igualmente repensar si para hacer frente al reto de esta mitad del siglo veinte nos ayudan los criterios con los que perseguiamos las variantes rurales, o si debemos someterlos al examen de su sentido, en tanto allanan o frustran, aceleran o retrasan la integración del campo con la ciudad, puesto que ahora se hallan vinculados por sistemas más dinámicos. Debemos, quizá, convenir en la importancia cé los enfoques etnolinguísticos. como una expresión de la utilidad del análisis interdisciplinario, etc. En otras palabras, pensamos que la "problemática de las lenguas nacionales" se traduce en la necesidad impostergable de alcanzar estas redef́niciones como instancia previa a todo plan de investigación $y$ al planteo de cualquier enmienda en la política educativa de la lengua oficial, sin omitir la elaboración de textos de enseñanza, en todos nuestros países.

Hasta hace muy poco. quienes trabajaban con las lenguas no europeas eran los únicos que aportaban las bases técnicas para, más alla del interés científico o erudito, saltar a la castellanización de los grupos idiomáticos de origen no euro. 
peo. Hoy estamos persuaciidos que desde esta otra vertiente, los hispanistas también sors tocados por una suerte de angustia social que se acopla a sus legítimas motivaciones científicas, y que por tal virtıd podrán insuflar un aliento vigoroso a sus estudios, si, comprendiendo el sentido de los cambios sociales, conciben la lengua nacional como un instrumento decisivo en el logro de la transformación de nuestras sociedades. Y si para conseguirlo admiten que el conocimiento objetivo de la lengua de las ciudades es el primer escalón que llevará a la castellanización de los hispanohablantes de normas substandard. C:erto es que esta tarea compete básicamente al esfuerzo de la pedagogía, pero cierto es también que ésta no dispondrá de satisfactorios textos de enseñanza si los lingüistas no cumplen su porción en la tarea, y si no ayudan en la elaboración y refinamiento de esos textos.

A la luz de estos datos, la admisión de una norma regional, de otra nacional y de una supranacional, construirá una escala que facilite la enseñanza, que desvele una realidad linguiística múltiple, que evite la discriminación y marginalización sociales, que fomente la cohesión interna y la comunicación externa, y que, colocando el viejo ideal unitario en su propio nivel, como remate de la pirámide constituída por los niveles menos extensos y yue le sirven de base, acierte con la instrumentación de un concepto de la lengua y de la disciplina que, desde el punto de vista social, se adhiera al irreversible proceso de cambio de nuestras sociedades, y contribuya a acelerarlo en tanto $y$ in cuanto sus investigaciones asciendan de lo regional ar lo unifario, y sus apficaciones promuevan la nivelación por referencia al reajuste urbano que, dadas sus características, reproduce en menor escala el proceso de acnmodaciones que, impulsacio por una distinta evaluación social, experimentan nuestras sociedades. 